\title{
Plasma IL-6/IL-10 Ratio and IL-8, LDH, and HBDH Level Predict the Severity and the Risk of Death in AIDS Patients with Pneumocystis Pneumonia
}

\author{
Jia Sun, ${ }^{1,2,3}$ Junwei Su, ${ }^{1,2,3}$ Yirui Xie, ${ }^{1,2,3}$ Michael T. Yin, ${ }^{4}$ Ying Huang, ${ }^{1,2,3}$ \\ Lijun Xu, ${ }^{1,2,3}$ Qihui Zhou, ${ }^{1,2,3}$ and Biao $\mathrm{Zhu}^{1,2,3}$ \\ ${ }^{1}$ State Key Laboratory for Diagnosis and Treatment of Infectious Diseases, Zhejiang, Hangzhou 310006, China \\ ${ }^{2}$ The First Affiliated Hospital, School of Medicine, Zhejiang University, Zhejiang, Hangzhou 310006, China \\ ${ }^{3}$ Collaborative Innovation Center for Diagnosis and Treatment of Infectious Diseases, Zhejiang, Hangzhou 310006, China \\ ${ }^{4}$ Division of Infectious Diseases, Columbia University Medical Center, New York, NY 10032, USA \\ Correspondence should be addressed to Biao Zhu; zhubiao1207@zju.edu.cn
}

Received 8 November 2015; Revised 20 April 2016; Accepted 9 June 2016

Academic Editor: Paola Nistico

Copyright (C) 2016 Jia Sun et al. This is an open access article distributed under the Creative Commons Attribution License, which permits unrestricted use, distribution, and reproduction in any medium, provided the original work is properly cited.

\begin{abstract}
Objective. To identify blood biomarkers to predict severity and mortality in AIDS PCP patients. Methods. Biomarkers including clinical parameters and plasma inflammatory cytokines were assessed in $32 \mathrm{HIV}$-infected patients with Pneumocystis pneumonia (PCP) at time of admission. Predictive value of the biomarkers for clinical severity and in-hospital mortality was evaluated by corresponding ROC curve. Results. Levels of CRP, WBC, LDH, HBDH, and Ferritin were significantly higher in the severe and nonsurvivor AIDS PCP patients. These important biochemical indicators have inverse correlation with oxygenation index, especially levels of $\operatorname{LDH}\left(P=0.008, R^{2}=0.258\right)$, $\operatorname{HBDH}\left(P=0.001, R^{2}=0.335\right)$, and Ferritin $\left(P=0.005, R^{2}=0.237\right)$. Plasma IL-8 and IL-6 levels were significantly higher in patients with $\mathrm{PaO}_{2} / \mathrm{FiO}_{2} \leq 200 \mathrm{mmHg}$ and nonsurvivors than in those with $\mathrm{PaO}_{2} / \mathrm{FiO}{ }_{2}>$ $200 \mathrm{mmHg}$ and survivors. Severe and nonsurvival groups showed higher ratio of mean IL-6/IL-10 level $(1.78 \pm 1.56, P<0.001 ; 1.11$ $\pm 0.72, P=0.043)$, larger AUC (95\% CI $0.781-1.000, P<0.001 ; 95 \%$ CI $0.592-0.917, P=0.043)$, and more significantly inverse correlation with the oxygenation index. Conclusion. Plasma IL-8, LDH, and HBDH levels and IL-6/IL-10 ratio could be helpful for early evaluation of the severity and predicting fatal outcomes in AIDS PCP patients.
\end{abstract}

\section{Introduction}

Pneumocystis pneumonia (PCP) is one of the most common opportunistic infections in HIV-infected patients with a substantial mortality rate. A recent cohort study in China by Xiao et al. found that the top three most common opportunistic infections (OI) of hospitalized HIV-infected patients were tuberculosis (32.5\%), candidiasis (29.3\%), and PCP (2.4\%), with PCP resulting in an in-hospital mortality rate of $33.1 \%$ [1]. The incidence of PCP has declined with combination of antiretroviral therapy (ART) and PCP prophylaxis. Nevertheless, PCP may occur in patients who are unaware of their HIV infection, are unable to reach medical care, or fail to adhere to PCP prophylaxis or ART $[1,2]$. PCP can also progress rapidly into respiratory failure in patients not immediately treated with appropriate therapy. Early diagnosis of PCP in AIDS patients can be challenging, especially when the CD4 count is unknown; therefore, empiric therapy is often initiated based upon nonspecific clinical manifestations while awaiting the results of diagnostic tests [3].

Hematologic parameters obtained by automated hematologic analyzer including C-reactive protein (CRP), erythrocyte sedimentation rate (ESR), procalcitonin (PCT), white blood cell (WBC), lactate dehydrogenase (LDH), hydroxybutyrate dehydrogenase $(\mathrm{HBDH}), \mathrm{D}$-dimer, and Ferritin are rapid to test. CRP and $\mathrm{LDH}$ have been evaluated in the diagnosis of AIDS PCP and prediction of PCP severity $[4,5]$ but have been found to have low predictive value. Since cytokine responses differ for different types of infections, therefore specific patterns of cytokine response may have 


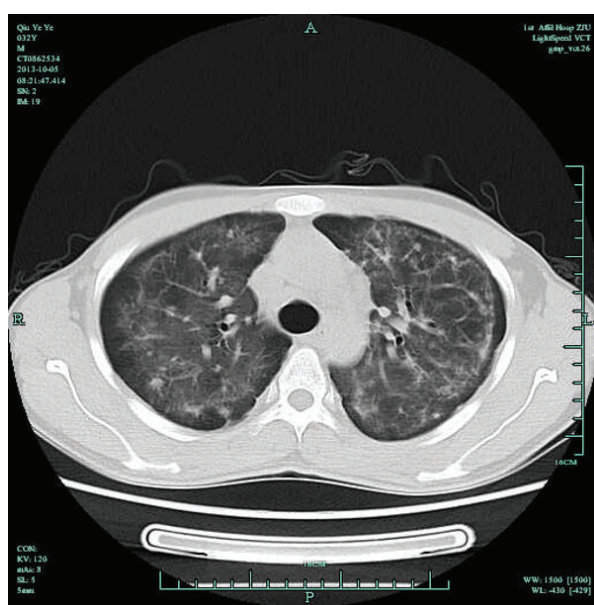

(a)

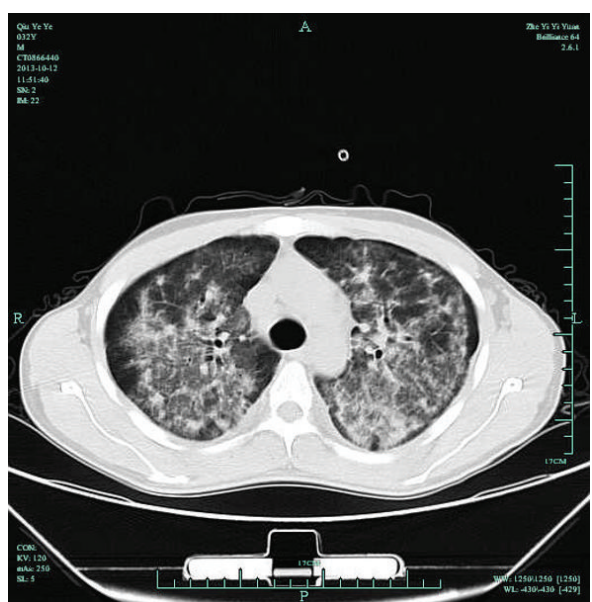

(b)

FIGURE 1: The chest images of computed tomography (CT) scan in the AIDS PCP patient. (a) shows bilateral, symmetric, interstitial, or granular opacities in typical case. (b) shows the opacities are perihilar and diffuse in severe case.

diagnostic and prognostic value [6]. Alveolar macrophages are the first line of host defense against $P$. jirovecii, leading to production of inflammatory chemokines IL- 8 and IL-6 $[7,8]$. Lung epithelial cells are the predominant cell type for Pneumocystis trophozoite and cyst adherence, which have been shown to produce IL-6, IL-8, and MCP-1 [9, 10]. Dendritic cells are also important effector immune cells in the lung; when exposed to Pneumocystis organisms, they displayed Th2 cytokine response, secreting IL-4 [11], and Thl-patterned cytokine response, secreting IL-1 $\beta$ and TNF- $\alpha$ [12]. In studies of mice infected with $P$. jirovecii, IFN- $\gamma$ was found to augment host defense by increasing nitric oxide synthesis of the macrophages [13]. Therefore, potential biomarker panels including cell markers, cytokines, coagulation factors, acute phase proteins, and other immune molecules may be more predictive than a single biomarker. Previous studies of biomarkers for AIDS PCP evaluated only individual biomarker such as IL-8 and a few combinations [14-16]. In this study, we evaluated a large panel of biomarkers to determine which ones may be of value in predicting evolution of PCP in HIV-infected persons.

\section{Materials and Methods}

2.1. Study Population. A total of 32 consecutive patients ( $>18$ years of age) diagnosed with AIDS PCP at infectious department of The First Affiliated Hospital of Zhejiang University were enrolled from March 2013 to July 2014. HIV infection was confirmed as recommended by Center for Disease Control and Prevention (CDC). History of AIDS diagnosis was determined according to HIV/AIDS management guidelines. Among 32 subjects, three subjects had ART exposure but stopped ART by themselves 1 to 2 years ago prior to admission. Diagnosis of PCP was based on the combination of symptoms, signs, laboratory data, arterial oxygenation at rest, and computed tomography (CT), including subacute onset of unproductive cough, fever, progressive dyspnea, and chest discomfort that worsens within days to weeks; arterial partial pressure of oxygen $\left(\mathrm{PaO}_{2}\right)$ lower than $65 \mathrm{mmHg}$ at time admission; and elevated level of lactate dehydrogenase ( $>245 \mathrm{U} / \mathrm{L})$. Typical chest CT imaging of AIDS PCP showed diffuse, bilateral, symmetrical interstitial infiltrates emanating from the hila in butterfly pattern (Figure 1) $[3,17]$. Exclusion criteria were as follows: (1) history of administration of agents with activity against PCP (including trimethoprim-sulfamethoxazole (SMZ-TMP), clindamycin, and caspofungin) or glucocorticoid therapy prior to enrollment; (2) evidence of other immune deficiencies (including malignancy, congenital immunodeficiency, and receipt of chemotherapy); and (3) evidence of immune reconstitution inflammatory syndrome (IRIS). We examined two clinical outcomes: severity of illness and survival; severity of illness was based on the worst oxygenation index during the hospitalization, defined as the ratio of $\mathrm{PaO}_{2} / \mathrm{FiO}_{2}(\mathrm{mmHg})$ and categorized into two groups: mild $\left(\mathrm{PaO}_{2} / \mathrm{FiO}_{2}>200 \mathrm{mmHg}\right)$ and severe $\left(\mathrm{PaO}_{2} / \mathrm{FiO}_{2} \leq 200 \mathrm{mmHg}\right)$. Subjects were also categorized into survival and nonsurvival groups based upon whether they survived the hospitalization.

Plasma was collected within the first 24 hours of admission for the measurement of targeted biomarkers. Written informed consents were obtained from all subjects. The study was conducted in accordance with the 1975 Declaration of Helsinki and approved by the Ethics Committee of The First Affiliated Hospital, School of Medicine, Zhejiang University, China.

\subsection{Clinical Biochemical Parameters and Inflammatory} Cytokines Examination. Biochemical parameters including WBC, eosinophil count, lymphocyte count, CRP, ESR, PCT, LDH, HBDH, D-dimer, and Ferritin were examined in a central laboratory of our hospital within 12 hours of admission. A $10 \mathrm{~mL}$ sample of peripheral blood was collected using the EDTA-anticoagulant tube. After centrifugation (1500 rpm for 5 minutes), the supernatant of blood was 
frozen and stored at $-80^{\circ}$ until it was analyzed. The levels of cytokines in the supernatant of blood were measured by the commercially enzyme-linked immunosorbent Human Platinum ELISA kits: IL-1 $\beta$, IL-2, IL-4, IL-6, IL-10, IL12, IL-17 $\alpha$, IL-18, MCP-1, and IFN- $\gamma$ (eBioscience, North America).

2.3. Statistical Analysis. Data were expressed as mean \pm SD. Kolmogorov-Smirnov tests were used to assess whether continuous variables are normally distributed, and then independent-samples $t$-test or nonparametric test (MannWhitney $U$ test) was chosen to compare groups. Spearman rank correlation coefficient analysis was used for linear correlation analysis. Evaluation of severity performance of biomarkers (see Table 4) was analyzed using receiver operation characteristic (ROC) curves. The ROC curves were compared using a nonparametric method. Significance was defined as $P<0.05$. Statistical analysis was performed using SPSS version 19 (SPSS, Armonk, New York, United States). All remaining statistical analyses were performed using MedCalc Statistical Software version 14.8.1 (MedCalc, Ostend, Belgium).

\section{Results}

3.1. Biochemical Makers in Severe Disease and Nonsurvivors. Clinical characteristics and baseline demographics of the 32 patients are shown in Table 1 . Mean age was $40.72 \pm$ 12.03 years, and mean CD4 count on admission was $87.14 \pm$ $14.46 / \mathrm{mm}^{3}$. None of the patients had taken PCP prophylaxis prior to admission and $90.6 \%$ were naive to ART (three subjects had previous exposure but had not been on ART for at least 1 year prior to admission). HIV-RNA levels were higher in patients with $\mathrm{PaO}_{2} / \mathrm{FiO}_{2} \leq 200 \mathrm{mmHg}$ than in those with $\mathrm{PaO}_{2} / \mathrm{FiO}_{2}>200 \mathrm{mmHg}$ (Table 1).

Blood levels of WBC, CRP, LDH, HBDH, and Ferritin were significantly higher in severe than in mild groups (Table 2). The levels of $\mathrm{LDH}, \mathrm{HBDH}$, and Ferritin were also markedly higher in nonsurvivors than in survivor groups (Table 3). In addition, ROC analysis of these biomarkers showed higher AUC in severity and nonsurvivors groups: LDH (95\% CI 0.636-0.956, $P=0.006$; 95\% CI 0.675-0.970, $P=0.01)$, HBDH (95\% CI $0.703-0.985, P=0.001 ; 95 \%$ CI $0.697-0.989, P=0.006$ ), and Ferritin (95\% CI 0.657-0.993, $P=0.002$; 95\% CI 0.541-0.991, $P=0.034$ ) (Figures 2(a) and 3(a)). There were significant inverse correlations between the oxygenation index and plasma level of $\mathrm{LDH}(P=0.008$, $\left.R^{2}=0.258\right)$, HBDH $\left(P=0.001, R^{2}=0.335\right)$, and Ferritin $\left(P=0.005, R^{2}=0.237\right)$ (Figures $4(\mathrm{~d}), 4(\mathrm{e})$, and 4(f)).

3.2. Increased Levels of IL-8 and IL-6 in Severe Disease and Nonsurvivors. Plasma levels of IL-6 and IL-8 were significantly higher in patients with $\mathrm{PaO}_{2} / \mathrm{FiO}_{2} \leq 200 \mathrm{mmHg}$ than in those with $\mathrm{PaO}_{2} / \mathrm{FiO}_{2}>200 \mathrm{mmHg}$ (Table 3). Nonsurvivors also had significantly higher blood levels of IL-8 compared with survivors (Table 5). The ROC curves constructed are listed in Figures 2 and 3. Among tested cytokines, IL-6 and IL- 8 had higher ROC in the severe
TABLE 1: Clinical characteristics and baseline demographics of AIDS PCP patients.

\begin{tabular}{|c|c|}
\hline Characteristics & \\
\hline Gender (M/F) & $32(32 / 0)$ \\
\hline Age, years & $40.72 \pm 12.03$ \\
\hline The most recent CD4 cell count & $87.14 \pm 14.46$ \\
\hline \multicolumn{2}{|l|}{ HIV-RNA, copies/mL } \\
\hline$>200 \mathrm{mmHg}, N=14$ & $23534.74 \pm 23616.33$ \\
\hline$\leq 200 \mathrm{mmHg}, N=8$ & $263789.65 \pm 208749.16$ \\
\hline $\mathrm{PaO}_{2} / \mathrm{FiO}_{2}$ before therapy & $208.96 \pm 90.03$ \\
\hline$>200 \mathrm{mmHg}, N=20$ & $268.92 \pm 44.26$ \\
\hline$\leq 200 \mathrm{mmHg}, N=12$ & $109.00 \pm 44.94$ \\
\hline \multicolumn{2}{|l|}{ Mode of transmission } \\
\hline Heterosexual transmission & $19(59.38 \%)$ \\
\hline Homosexual transmission & $12(37.50 \%)$ \\
\hline Bisexual transmission & $1(3.12 \%)$ \\
\hline \multicolumn{2}{|l|}{ Underline disease } \\
\hline Candidiasis (oral/pulmonary) & $15(10 / 5)$ \\
\hline Syphilis (neurosyphilis) & $6(1)$ \\
\hline Aspergillosis (esophagus/pulmonary) & $6(5 / 1)$ \\
\hline Tuberculosis (intestinal/pulmonary) & $2(1 / 1)$ \\
\hline Tinea cruris & 1 \\
\hline Herpes zoster & 1 \\
\hline CMV retinitis & 1 \\
\hline Seborrheic dermatitis & 1 \\
\hline Hematology disorders & 1 \\
\hline Hepatic insufficiency & 1 \\
\hline Psychonosema & 1 \\
\hline Nutritional deficiencies & 1 \\
\hline Hypokalemia & 1 \\
\hline Pneumothorax & 1 \\
\hline COPD & 1 \\
\hline Hypertension & 1 \\
\hline \multicolumn{2}{|l|}{ Treatment } \\
\hline SMZ-TMP prophylaxis & $0(0 \%)$ \\
\hline HARRT before PCP & $3(9.40 \%)$ \\
\hline Anti-PCP therapy & $32(100 \%)$ \\
\hline SMZ-TMP & $32(100 \%)$ \\
\hline Clindamycin & $32(100 \%)$ \\
\hline Caspofungin & $11(34.38 \%)$ \\
\hline Antibiotic therapy & $29(90.63 \%)$ \\
\hline Antifungal therapy & $29(90.63 \%)$ \\
\hline Glucocorticoid therapy & $30(93.75 \%)$ \\
\hline Mechanical ventilation & $2(6.25 \%)$ \\
\hline \multicolumn{2}{|l|}{ Clinical outcome } \\
\hline Survivor & $25(78.12 \%)$ \\
\hline Nonsurvivor & $7(21.88 \%)$ \\
\hline
\end{tabular}

and nonsurvival group. There were also significant inverse correlations between the oxygenation index and plasma levels of IL-6 $\left(P=0.001, R^{2}=0.210\right)$ and IL-8 $(P=0.001$, $R^{2}=0.137$ ) (Figures $4(\mathrm{~b})$ and $4(\mathrm{c})$ ). 
TABLE 2: Comparisons of laboratory data between $\mathrm{PaO}_{2} / \mathrm{FiO}_{2} \leq 200$ and $>200 \mathrm{mmHg}$.

\begin{tabular}{lcccc}
\hline Laboratory data & Normal ranges & $\mathrm{PaO}_{2} / \mathrm{FiO}_{2} \leq 200 \mathrm{mmHg},(\mathrm{N}=12)$ & $\mathrm{PaO}_{2} / \mathrm{FiO}_{2}>200 \mathrm{mmHg},(\mathrm{N}=20)$ & $P$ value \\
\hline CRP & $0.00-8.00 \mathrm{mg} / \mathrm{L}$ & $75.73 \pm 47.72$ & $35.38 \pm 35.97$ & 0.011 \\
ESR & $0-15 \mathrm{~mm} / \mathrm{h}$ & $59.50 \pm 32.03$ & $0.00 \pm 24.40$ & $0.05 \pm 0.09$ \\
$\mathrm{PCT}$ & $0.00-0.50 \mathrm{ng} / \mathrm{mL}$ & $0.30 \pm 0.32$ & $4.96 \pm 1.67$ & 0.021 \\
$\mathrm{WBC}$ & $4.0-10.0 * 10^{9} / \mathrm{L}$ & $7.94 \pm 2.89$ & $0.11 \pm 0.20$ & 0.005 \\
Eosinophil count & $0.20-0.50 * 10^{9} / \mathrm{L}$ & $0.07 \pm 0.12$ & $0.88 \pm 0.39$ & 0.871 \\
Lymphocyte count & $0.8-4.0 * 10^{9} / \mathrm{L}$ & $0.63 \pm 0.33$ & $335.20 \pm 130.73$ \\
LDH & $109-245 \mathrm{U} / \mathrm{L}$ & $529.50 \pm 246.73$ & $276.55 \pm 101.18$ & 0.071 \\
HBDH & $72-182 \mathrm{U} / \mathrm{L}$ & $443.00 \pm 168.54$ & $1995.06 \pm 3732.31$ & 0.007 \\
D-dimer & $0-700 \mathrm{ug} / \mathrm{L}$ & $2904.17 \pm 3668.19$ & $696.12 \pm 344.71$ \\
Ferritin & $7.0-323.0 \mathrm{ng} / \mathrm{mL}$ & $1698.33 \pm 1590.71$ & 0.001 \\
\hline
\end{tabular}

Data are expressed as mean and SD. CRP: C-reactive protein; ESR: erythrocyte sedimentation rate; PCT: procalcitonin; WBC: white blood cell; LDH: lactate dehydrogenase; HBDH: hydroxybutyrate dehydrogenase.

TABle 3: Comparisons of cytokines between $\mathrm{PaO}_{2} / \mathrm{FiO}_{2} \leq 200$ and $>200 \mathrm{mmHg}$.

\begin{tabular}{lccc}
\hline Cytokines & $\mathrm{PaO}_{2} / \mathrm{FiO}_{2} \leq 200 \mathrm{mmHg},(N=12)$ & $\mathrm{PaO}_{2} / \mathrm{FiO}_{2}>200 \mathrm{mmHg},(N=20)$ & $P$ value \\
\hline $\mathrm{IL}-6, \mathrm{pg} / \mathrm{mL}$ & $6.58 \pm 6.87$ & $1.42 \pm 1.86$ & $3.62 \pm 6.56$ \\
$\mathrm{IL}-1 \beta, \mathrm{pg} / \mathrm{mL}$ & $1.11 \pm 2.04$ & $3.01 \pm 3.38$ & 0.178 \\
$\mathrm{IL}-8, \mathrm{pg} / \mathrm{mL}$ & $7.41 \pm 6.52$ & $7.73 \pm 9.40$ & 0.001 \\
$\mathrm{IL}-10, \mathrm{pg} / \mathrm{mL}$ & $3.85 \pm 2.50$ & $0.18 \pm 0.25$ & 0.175 \\
$\mathrm{IL}-17 \alpha, \mathrm{pg} / \mathrm{mL}$ & $0.34 \pm 0.28$ & $334.16 \pm 176.31$ \\
$\mathrm{IL}-18, \mathrm{pg} / \mathrm{mL}$ & $588.52 \pm 463.57$ & $143.28 \pm 99.03$ \\
$\mathrm{MCP}-1, \mathrm{pg} / \mathrm{mL}$ & $198.85 \pm 160.17$ & $2.95 \pm 5.56$ & 0.102 \\
IFN $\gamma, \mathrm{pg} / \mathrm{mL}$ & $0.56 \pm 1.02$ & $1.43 \pm 3.24$ & 0.091 \\
$\mathrm{IL}-4, \mathrm{pg} / \mathrm{mL}$ & $1.17 \pm 1.61$ & $0.32 \pm 0.39$ \\
IL-12, pg/mL & $0.24 \pm 0.40$ & $0.96 \pm 1.86$ \\
IL-8/IL-10 & $3.08 \pm 3.52$ & $0.76 \pm 1.48$ \\
IL-1 $\beta / \mathrm{IL}-10$ & $0.20 \pm 0.30$ & $33.75 \pm 36.66$ & 0.233 \\
MCP-1/IL-10 & $75.26 \pm 104.70$ & $0.34 \pm 0.58$ \\
IL-6/IL-10 & $1.78 \pm 1.56$ &
\end{tabular}

IL: interleukin; MCP1: monocyte chemoattractant protein 1; IFN $\gamma$ : interferon $\gamma$.

TABLE 4: Comparisons of biomarkers between nonsurvivors and survivors of AIDS PCP patients.

\begin{tabular}{lccc}
\hline Laboratory data & Nonsurvivors $(N=7)$ & Survivors $(N=25)$ & $P$ value \\
\hline CRP, mg/L & $73.16 \pm 49.78$ & $44.17 \pm 42.02$ & 0.131 \\
ESR, $\mathrm{mm} / \mathrm{h}$ & $41.57 \pm 27.21$ & $60.92 \pm 26.03$ & 0.095 \\
$\mathrm{PCT}, \mathrm{ng} / \mathrm{mL}$ & $0.21 \pm 0.22$ & $0.13 \pm 0.24$ & 0.080 \\
$\mathrm{WBC}, * 10^{9} / \mathrm{L}$ & $7.73 \pm 3.44$ & $5.61 \pm 2.20$ & 0.057 \\
Eosinophil & $0.09 \pm 0.15$ & $0.09 \pm 0.18$ & 0.703 \\
Lymphocyte & $0.61 \pm 0.33$ & $0.83 \pm 0.39$ & 0.194 \\
LDH, U/L & $586.29 \pm 289.93$ & $358.16 \pm 142.67$ & 0.006 \\
HBDH, U/L & $486.86 \pm 184.58$ & $297.56 \pm 114.45$ & 0.002 \\
D-dimer, ug/L & $4286.86 \pm 4365.60$ & $1789.72 \pm 3356.78$ & 0.047 \\
Ferritin, ng/mL & $1789.83 \pm 1878.50$ & $870.95 \pm 702.22$ & 0.033 \\
\hline
\end{tabular}

SD, AIDS, PCP, CRP, ESR, PCT, WBC, LDH, and HBDH as shown in Tables 1 and 2. 
TABLE 5: Comparisons of cytokines between nonsurvivors and survivors of AIDS PCP patients.

\begin{tabular}{lccc}
\hline Cytokines & Nonsurvivors $(N=7)$ & Survivors $(N=25)$ & $P$ value \\
\hline IL-6, pg/mL & $4.85 \pm 5.32$ & $2.93 \pm 4.98$ & 0.075 \\
IL-1 $\beta, p g / m L$ & $1.55 \pm 2.57$ & $2.99 \pm 5.55$ & 0.609 \\
IL-8, pg/mL & $7.22 \pm 6.51$ & $3.95 \pm 4.76$ & 0.017 \\
IL-10, pg/mL & $4.31 \pm 2.77$ & $6.83 \pm 8.62$ & 0.632 \\
IL-17 $\alpha, \mathrm{pg} / \mathrm{mL}$ & $0.39 \pm 0.33$ & $0.20 \pm 0.24$ & 0.109 \\
IL-18, pg/mL & $749.28 \pm 540.36$ & $340.02 \pm 179.33$ & 0.091 \\
MCP-1, pg/mL & $164.16 \pm 126.94$ & $164.11 \pm 128.29$ & 0.093 \\
IFN $\gamma, p g / m L$ & $0.78 \pm 1.28$ & $2.41 \pm 5.07$ & 0.431 \\
IL-4, pg/mL & $1.36 \pm 1.81$ & $1.32 \pm 2.95$ & 0.279 \\
IL-12, pg/mL & $0.30 \pm 0.47$ & $0.28 \pm 0.38$ & 0.826 \\
IL-8/IL-10 & $2.45 \pm 2.69$ & $1.56 \pm 2.8$ & 0.059 \\
IL-1 $\beta / \mathrm{IL}-10$ & $0.23 \pm 0.36$ & $0.64 \pm 1.32$ & 0.658 \\
MCP1/IL-10 & $49.12 \pm 26.97$ & $49.37 \pm 80.28$ & 0.210 \\
IL-6/IL-10 & $1.11 \pm 0.72$ & $0.82 \pm 1.37$ & 0.043 \\
\hline
\end{tabular}

SD, IL, MCP1, and IFN $\gamma$ as shown in Tables 1 and 2.

3.3. IL-6/IL-10 Ratio Was Intensively Related to Severe and Nonsurvival AIDS PCP Patients. The ratio between antiinflammatory cytokines IL-10 and other proinflammatory cytokines IL-6, IL-8, IL-1 $\beta$, and MCP-1 revealed higher levels both in the severe group and in nonsurvival groups (Tables 3 and 5). Severity and nonsurvivors groups had a higher ratio of IL-6/IL-10 $(1.78 \pm 1.56, P=0.000 ; 1.11 \pm 0.72, P=0.043)$ (shown in Tables 3 and 5), higher AUC (95\% CI 0.781-1.000, $P=0.000$; 95\% CI 0.592-0.917, $P=0.043$ ) (Figures 2(c) and $3(\mathrm{c})$ ), and more significantly inverse correlation with the oxygenation index $\left(P=0.01, R^{2}=0.276\right)$ (Figure $\left.4(\mathrm{a})\right)$.

\section{Discussion}

Although LDH is a nonspecific biomarker and also increases in many other diseases, an elevated LDH level has been noted in many patients with PCP [18] and has been utilized for diagnosis of PCP [19-22]. Few articles or guidelines have assessed the utility of $\mathrm{LDH}$ in predicting severity of disease progression. In the present study, we observed significantly higher elevated levels of LDH in PCP patients developing severe respiratory compromise with $\mathrm{PaO}_{2} / \mathrm{FiO}_{2} \leq 200 \mathrm{mmHg}$ than those in those mild disease with $\mathrm{PaO}_{2} / \mathrm{FiO}_{2}>200 \mathrm{mmHg}$. We also showed a significant inverse correlation between the oxygenation index and $\mathrm{LDH}\left(P=0.008, R^{2}=0.258\right)$. The activity of $\mathrm{HBDH}$ is increased with PCP, correlating positively with $\mathrm{LDH}\left(P=0.000, R^{2}=0.882\right.$, data not shown) and negatively with oxygenation index $(P=0.001$, $R^{2}=0.335$ ), indicating that $\mathrm{HBDH}$ is likely to be reflection of the underlying lung inflammation. $\mathrm{HBDH}$ level seems to be another potential biochemical parameter for prediction of AIDS PCP severity and mortality.

Biochemical parameters such as CRP and D-dimer obtained via hematologic analyzer are rapid and require small quantities of blood samples. Similar to previous studies [5, 23-25], we found CRP and D-dimer to be useful parameters for the diagnosis and prediction of PCP severity. In our study, CRP levels were higher in patients with $\mathrm{PaO}_{2} / \mathrm{FiO}_{2} \leq$ $200 \mathrm{mmHg}$, and D-dimer levels were higher in nonsurvivors.

Theoretically, abnormal exaggeration of proinflammatory or anti-inflammatory cytokine response can be harmful to the host, leading to respiratory distress syndrome, shock, multiorgan failure, or death. Therefore, quantitation of the inflammatory response may have prognostic implications [26]. The results of a previous study indicated that PCP patients had higher levels of proinflammatory cytokines compared to controls, but anti-inflammatory cytokines had a variable response. Some proinflammatory/anti-inflammatory ratios were valuable in assessing the severity of PCP and predicting the outcome of the patients [27].

IL- 8 is correlated with both neutrophil infiltration of the lung and impaired gas exchange during severe PCP. Recent studies of PCP reported that the level of IL-8 in bronchoalveolar lavage fluid (BALF) and plasma may serve as a predictor of severe respiratory failure and death $[15$, 16]. Furthermore, plasma levels of IL- 8 were found to be significantly higher in severe non-AIDS PCP [27]. In agreement with previous reports, the present study indicated that the blood level of IL-8 differed between subjects with $\mathrm{PaO}_{2} / \mathrm{FiO}_{2} \leq 200 \mathrm{mmHg}$ and $\mathrm{PaO}_{2} / \mathrm{FiO}_{2}>200 \mathrm{mmHg}$, correlated inversely with oxygen index, and also differed between survivors and nonsurvivors [15].

IL-6 is a proinflammatory cytokine that is important for $\mathrm{B}$ cells as well as promoting CD4 $\mathrm{T}$ cell proliferation and survival [28]. In animal experiments, IL-6 levels were elevated in severe combined immunodeficient mice with $P$. carinii pneumonia compared with levels in $P$. carinii-free mice [29]. Kobayashi et al. [11] reported that BALF levels of IL- 6 were higher in immunocompromised patients with PCP than in immunocompromised and immunocompetent patients without PCP [30]. In our study, plasma IL-6 levels were higher in patients with $\mathrm{PaO}_{2} / \mathrm{FiO}_{2} \leq 200 \mathrm{mmHg}$ than in those with $\mathrm{PaO}_{2} / \mathrm{FiO}_{2}>200 \mathrm{mmHg}$ but did differ between survivors and nonsurvivors. IL-10 is an anti-inflammatory cytokine produced primarily by antigen-presenting cells, 

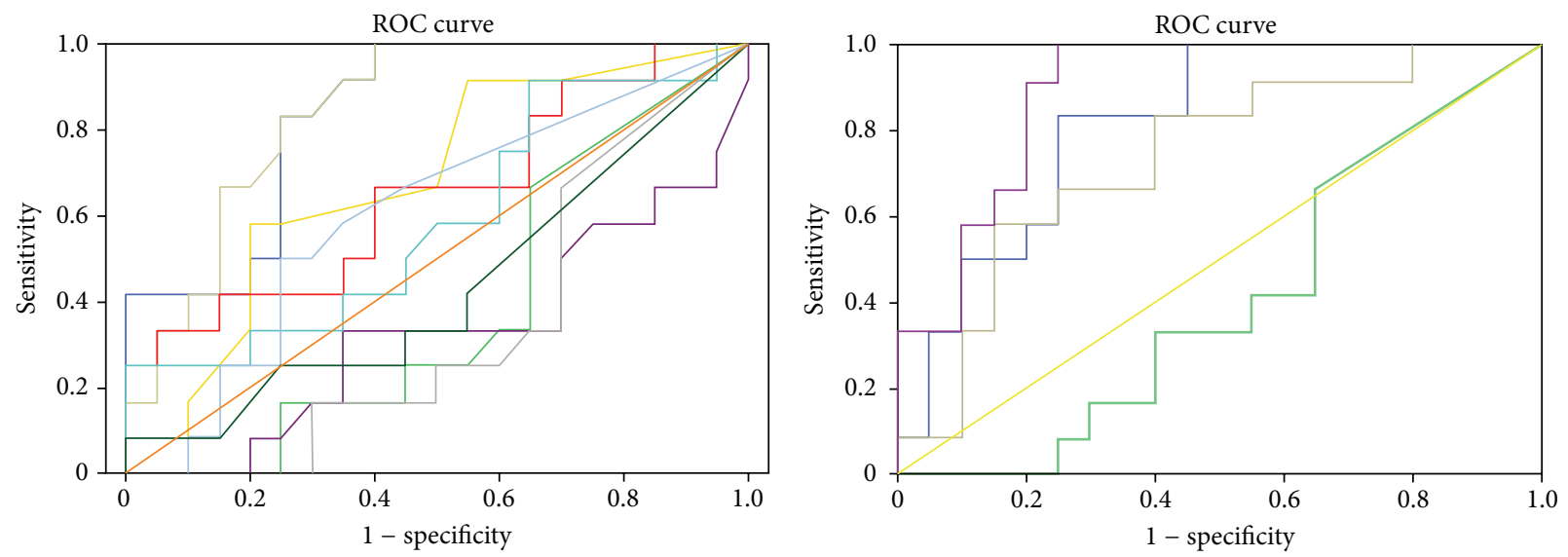

Source of the curve

$\begin{array}{ll}\text { Source of the curve } & \text { MCP-1 } \\ \text { IL-6 } & \text { IL-1B } \\ \text { IL-8 } & \text { IFNr } \\ \text { IL-8 } & \text { IL-4 } \\ \text { IL-10 } & \text { IL-12 } \\ \text { IL-17A } & \text { - Reference line } \\ \text { IL-18 } & \end{array}$

Source of the curve

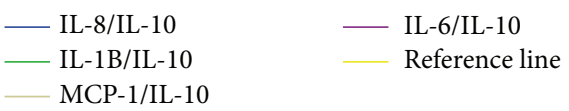

(b)

(a)
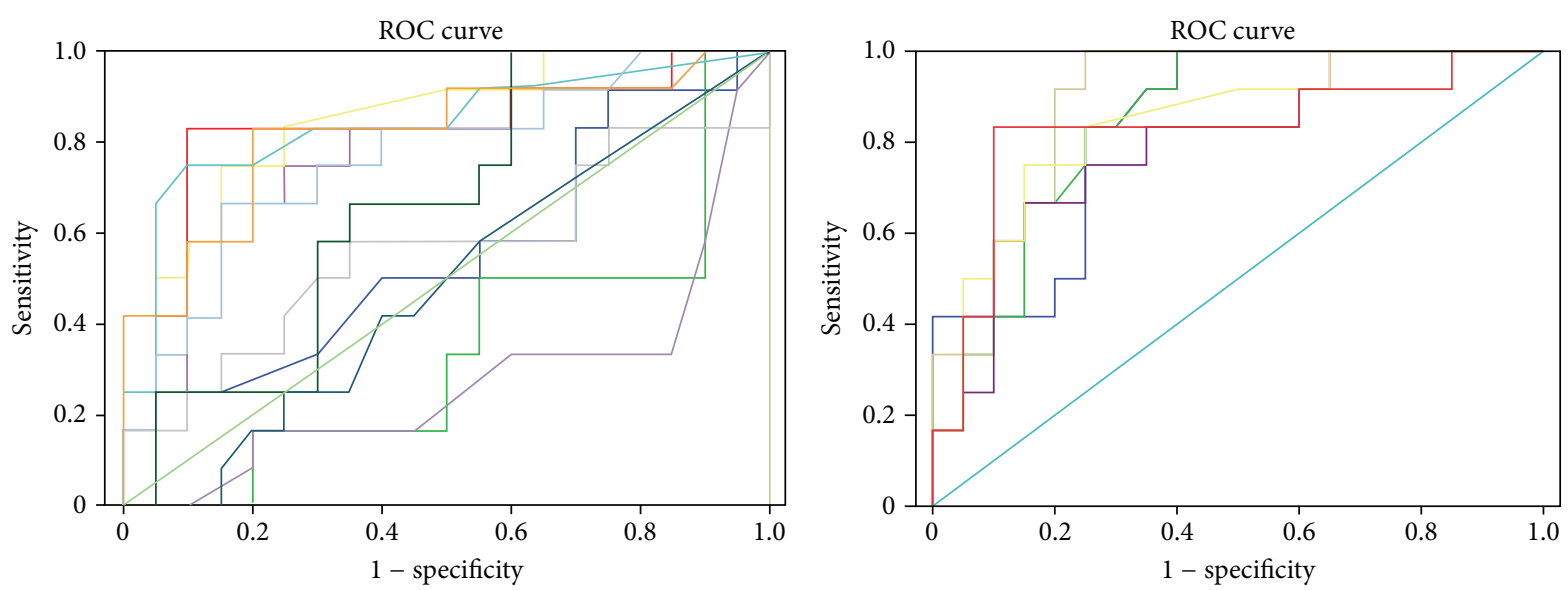

Source of the curve

$\begin{array}{ll}- \text { Age } & \text { - ESR } \\ -\mathrm{CD} 4 & \text { CRP } \\ \mathrm{PaO}_{2} / \mathrm{FiO}_{2} & -\mathrm{D} \text {-dimer } \\ -\mathrm{LDH} & -\mathrm{WBC} \\ \mathrm{HBDH} & - \text { Lcyte } \\ \text { HeP } & - \text { Ecyte } \\ \mathrm{FCT} & \text { - Reference line }\end{array}$

Source of the curve

$\begin{array}{ll}- \text { IL-6 } & \text { HBDH } \\ \text { IL-8 } & - \text { FeP } \\ \text { IL-6/IL-10 } & - \text { Reference line }\end{array}$

(c)

(d)

FIGURE 2: Receiver operating characteristic (ROC) curve analysis of biomarkers in lighter severity $\left(\mathrm{PaO}_{2} / \mathrm{FiO}_{2} \leq 200 \mathrm{mmHg}, \mathrm{N}=12\right)$ and heavier severity $\left(\mathrm{PaO}_{2} / \mathrm{FiO}_{2}>200 \mathrm{mmHg}, \mathrm{N}=20\right.$ ) AIDS PCP. (a) LDH (95\% CI 0.636-0.956, $P=0.006$ ), HBDH (95\% CI 0.703$0.985, P=0.001)$, and FeP (95\% CI 0.657-0.993, $P=0.002)$ showing much higher AUC in severity AIDS PCP groups. (b) IL-6 (95\% CI $0.704-0.976, P=0.002)$ and IL-8 (95\% CI 0.713-0.978, $P=0.001)$ showing much higher AUC in severity AIDS PCP groups. (c) IL-8/IL-10 (95\% CI 0.671-0.962, $P=0.003$ ), MCP-1/IL-10 (95\% CI 0.559-0.916, $P=0.027$ ), and IL-6/IL-10 (95\% CI 0.781-1.000, $P=0.000)$ showing much higher AUC in severity AIDS PCP groups. (d) Much better six biomarkers' ROC curves shown together (WBC: white blood cell; LDH: lactate dehydrogenase; HBDH: hydroxybutyrate dehydrogenase; IL: interleukin; MCP-1: monocyte chemoattractant protein 1, and FeP: Ferritin protein). 

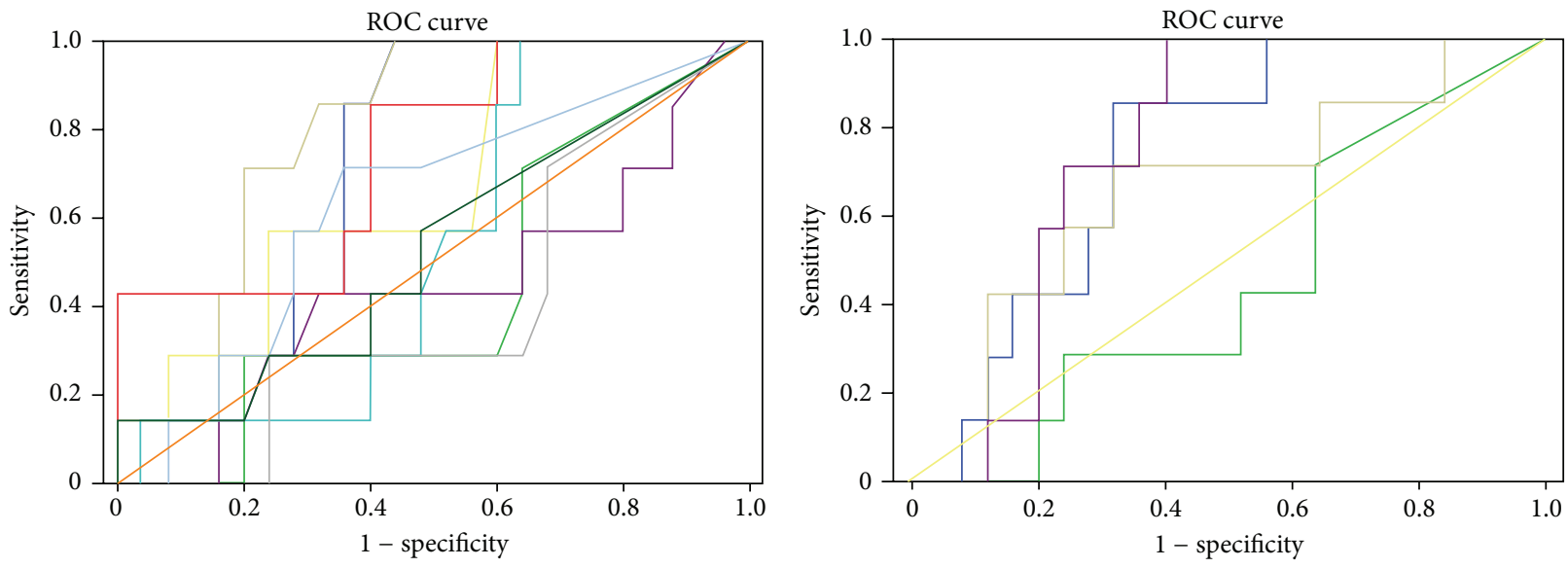

Source of the curve

$\begin{array}{ll}\text { IL-6 } & \text { MCP-1 } \\ \text { IL-1B } & \text { IFNr } \\ \text { IL-8 } & - \text { IL-4 } \\ \text { IL-10 } & - \text { IL-12 } \\ \text { IL-17A } & - \text { Reference line } \\ \text { IL-18 } & \end{array}$

(a)
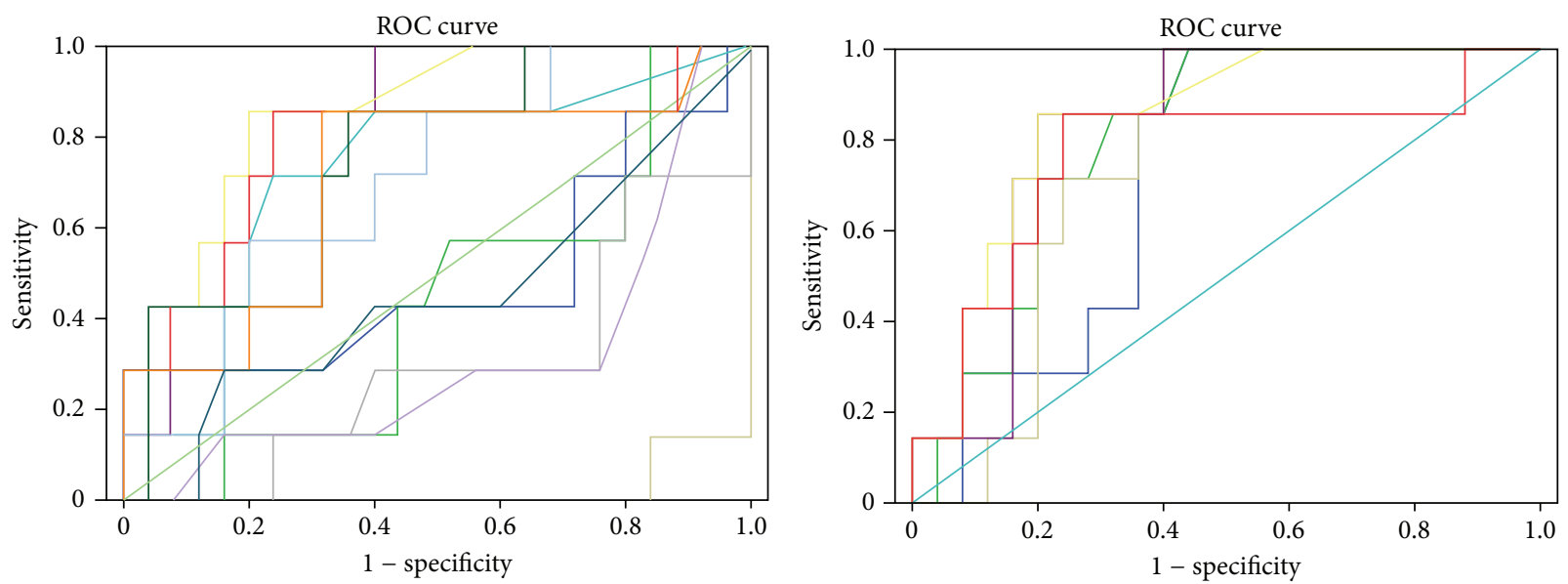

Source of the curve

- Age
$-\mathrm{CD} 4$
$-\mathrm{PaO}_{2} / \mathrm{FiO}_{2}$
$-\mathrm{LDH}$
$\mathrm{HBDH}$
$-\mathrm{FeP}$
$\mathrm{PCT}$

ESR

- CRP

— D-dimer

- WBC

- Lcyte

_ Ecyte

_ Reference line

(c)

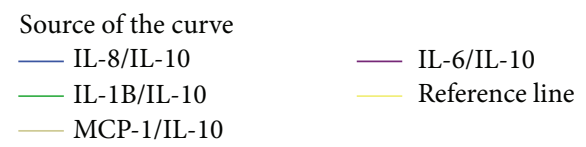

(b)

$\begin{array}{ll}\text { Source of the curve } & \\ \text { IL-6 } & \text { HBDH } \\ \text { IL-8 } & \text { FeP } \\ \text { IL-6/IL-10 } & \text { LDH }\end{array}$

(d)

FIGURE 3: Receiver operating characteristic (ROC) curve analysis of biomarkers in nonsurvivors $(N=7)$ and survivors $(N=25)$ AIDS PCP. (a) LDH (95\% CI $0.675-0.970, P=0.010)$, HBDH (95\% CI 0.797-0.989, $P=0.006)$, and FeP (95\% CI 0.541-0.991, $P=0.034)$ showing much higher AUC in nonsurvivors AIDS PCP groups. (b) IL-6 (95\% CI 0.547-0.898, $P=0.075)$ and IL-8 $(95 \%$ CI $0.647-0.953, P=0.017)$ showing much higher AUC in nonsurvivors AIDS PCP groups. (c) IL-8/IL-10 (95\% CI 0.561-0.963, $P=0.057$ ) and IL-6/IL-10 (95\% CI $0.592-0.917, P=0.043$ ) showing much higher AUC in nonsurvivors AIDS PCP groups. (d) Much better six biomarkers' ROC curves shown together (WBC: white blood cell; LDH: lactate dehydrogenase; HBDH: hydroxybutyrate dehydrogenase; IL: interleukin; MCP-1: monocyte chemoattractant protein 1, and FeP: Ferritin protein). 


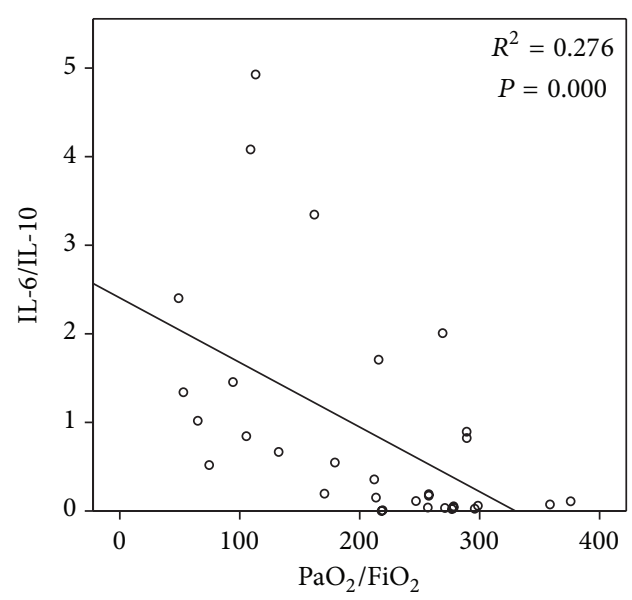

(a)

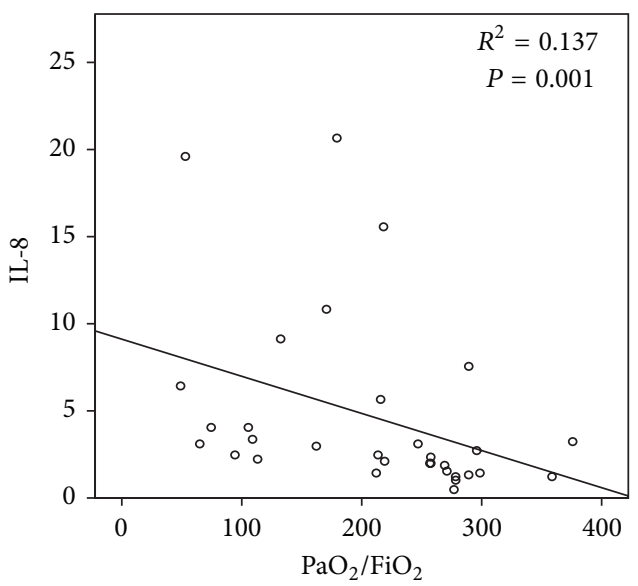

(c)

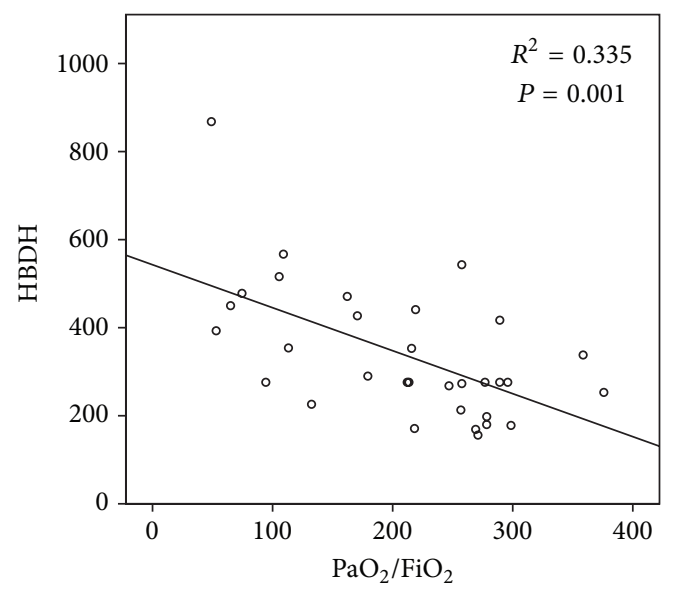

(e)

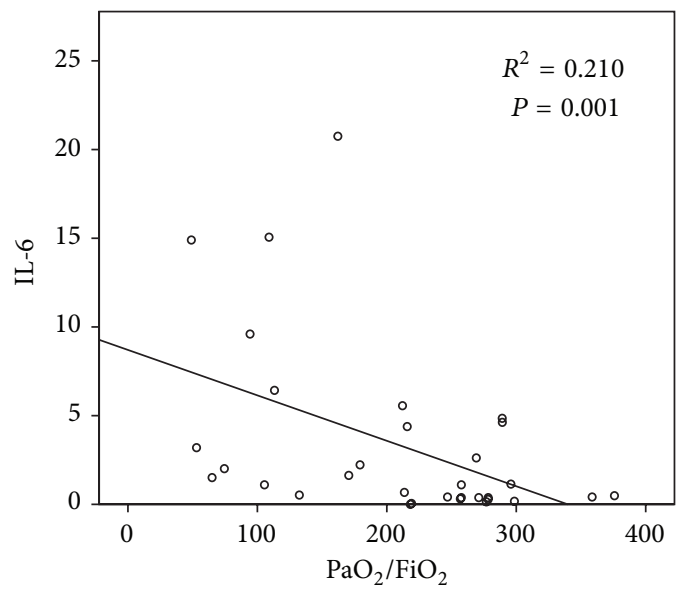

(b)

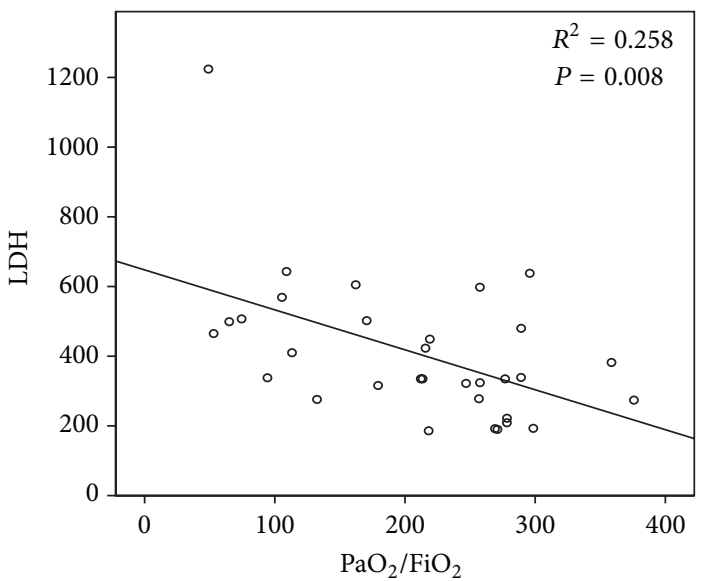

(d)

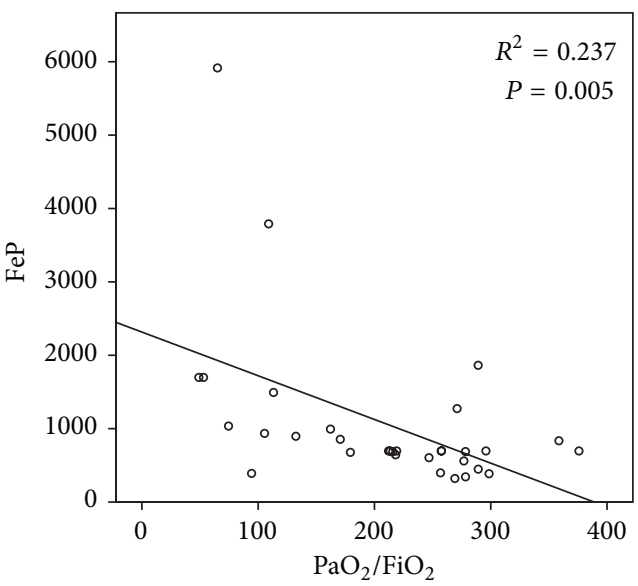

(f)

FIgURE 4: The correlation analysis of the oxygenation index with LDH, HBDH, FeP, IL-8, and IL-6 level and IL-6/IL-10 ratio. (a) IL-6/IL-10 $\left(P=0.000, R^{2}=0.276\right)$; (b) IL-6 $\left(P=0.001, R^{2}=0.210\right)$; (c) IL-8 $\left(P=0.001, R^{2}=0.137\right)$; (d) LDH $\left(P=0.008, R^{2}=0.258\right) ;(\mathrm{e}) \mathrm{HBDH}$ $\left(P=0.001, R^{2}=0.335\right)$; and (f) Ferritin $\left(P=0.005, R^{2}=0.237\right)$.

which exerts negative regulatory effects on proinflammatory cytokines by downregulating their synthesis [31]. IL-10 is released in the lungs of experimental animals with PCP [32] and also in humans [33], resulting in decreased Pneumocystisdriven pulmonary inflammation and improved survival.
In our study, IL-10 level in patients with $\mathrm{PaO}_{2} / \mathrm{FiO}_{2}>$ $200 \mathrm{mmHg}$ were higher than that in $\mathrm{PaO}_{2} / \mathrm{FiO}_{2} \leq 200 \mathrm{mmHg}$ and similarly in survivors compared to nonsurvivors. Surprisingly, we found higher blood levels of IL-6/IL-10 ratio in patients with $\mathrm{PaO}_{2} / \mathrm{FiO}_{2} \leq 200 \mathrm{mmHg}$ and in nonsurvivors. 
Furthermore, IL-6/IL-10 had the highest AUC and correlated inversely with the oxygenation index $\left(P<0.001, R^{2}=0.276\right)$.

In conclusion, our data suggest that detection of plasma IL-8 levels and IL-6/IL-10 ratio combined with LDH and $\mathrm{HBDH}$ can predict the severity of PCP risk of death in AIDS patients with PCP. In developing countries where resources for mechanical ventilation are limited, assessment and risk stratification on admission, using commonly available laboratory biomarkers, may be particularly helpful for management of PCP.

\section{Consent}

Written consent was obtained from the patients.

\section{Competing Interests}

All authors declare no potential conflict of interests.

\section{Acknowledgments}

This work was funded by National Special Research Program for Important Infectious Diseases (nos. 2013ZX10001004002-003, 2014ZX10001002-002-002).

\section{References}

[1] J. Xiao, G. Gao, Y. Li et al., "Spectrums of opportunistic infections and malignancies in HIV-infected patients in tertiary care hospital, China," PLoS ONE, vol. 8, no. 10, Article ID e75915, 2013.

[2] C. F. Thomas Jr. and A. H. Limper, "Pneumocystis pneumonia," The New England Journal of Medicine, vol. 350, no. 24, pp. 24872498, 2004.

[3] J. E. Kaplan, C. Benson, K. K. Holmes, J. T. Brooks, A. Pau, and H. Masur, "Guidelines for prevention and treatment of opportunistic infections in HIV-infected adults and adolescents: recommendations from CDC, the National Institutes of Health, and the HIV Medicine Association of the Infectious Diseases Society of America," MMWR Recommendations and Reports, vol. 58, no. 4, pp. 1-207, 2009.

[4] M. K. Zaman and D. A. White, "Serum lactate dehydrogenase levels and pneumocystis carinii pneumonia. Diagnostic and prognostic significance," The American Review of Respiratory Disease, vol. 137, no. 4, pp. 796-800, 1988.

[5] E. K. Sage, M. Noursadeghi, H. E. Evans et al., "Prognostic value of C-reactive protein in $\mathrm{HIV}$-infected patients with Pneumocystis jirovecii pneumonia," International Journal of STD \& AIDS, vol. 21, no. 4, pp. 288-292, 2010.

[6] C. Gabay and I. Kushner, "Acute-phase proteins and other systemic responses to inflammation," The New England Journal of Medicine, vol. 340, no. 6, pp. 448-454, 1999.

[7] J. Zhang, J. Zhu, A. Imrich, M. Cushion, T. B. Kinane, and H. Koziel, "Pneumocystis activates human alveolar macrophage NF- $\kappa \mathrm{B}$ signaling through mannose receptors," Infection and Immunity, vol. 72, no. 6, pp. 3147-3160, 2004.

[8] R. Vassallo, T. J. Kottom, J. E. Standing, and A. H. Limper, "Vitronectin and fibronectin function as glucan binding proteins augmenting macrophage responses to Pneumocystis carinii,"
American Journal of Respiratory Cell and Molecular Biology, vol. 25, no. 2, pp. 203-211, 2001.

[9] S. T. Pottratz, S. Reese, and J. L. Sheldon, "Pneumocystis carinii induces interleukin 6 production by an alveolar epithelial cell line," European Journal of Clinical Investigation, vol. 28, no. 5, pp. 424-429, 1998.

[10] T. L. Benfield, B. Lundgren, J. H. Shelhamer, and J. D. Lundgren, "Pneumocystis carinii major surface glycoprotein induces interleukin-8 and monocyte chemoattractant protein-1 release from a human alveolar epithelial cell line," European Journal of Clinical Investigation, vol. 29, no. 8, pp. 717-722, 1999.

[11] H. Kobayashi, S. Worgall, T. P. O’Connor, and R. G. Crystal, "Interaction of Pneumocystis carinii with dendritic cells and resulting host responses to $P$. carinii," Journal of Immunotherapy, vol. 30, no. 1, pp. 54-63, 2007.

[12] E. M. Carmona, R. Vassallo, Z. Vuk-Pavlovic, J. E. Standing, T. J. Kottom, and A. H. Limper, "Pneumocystis cell wall $\beta$-glucans induce dendritic cell costimulatory molecule expression and inflammatory activation through a Fas-Fas ligand mechanism," The Journal of Immunology, vol. 177, no. 1, pp. 459-467, 2006.

[13] T. Ishimine, K. Kawakami, A. Nakamoto, and A. Saito, "Analysis of cellular response and gamma interferon synthesis in bronchoalveolar lavage fluid and lung homogenate of mice infected with Pneumocystis carinii," Microbiology and Immunology, vol. 39, no. 1, pp. 49-58, 1995.

[14] N. Benito, A. Moreno, X. Filella et al., "Inflammatory responses in blood samples of human immunodeficiency virus-infected patients with pulmonary infections," Clinical and Diagnostic Laboratory Immunology, vol. 11, no. 3, pp. 608-614, 2004.

[15] T. L. Benfield, J. Vestbo, J. Junge, T. L. Nielsen, A.-M. B. Jensen, and J. D. Lundgren, "Prognostic value of interleukin-8 in AIDSassociated Pneumocystis carinii pneumonia," American Journal of Respiratory and Critical Care Medicine, vol. 151, no. 4, pp. 1058-1062, 1995.

[16] C.-W. Chou, F.-C. Lin, H.-C. Tsai, and S.-C. Chang, "The impact of concomitant pulmonary infection on immune dysregulation in Pneumocystis jirovecii pneumonia," BMC Pulmonary Medicine, vol. 14, article 182, 2014.

[17] H. Masur, J. T. Brooks, C. A. Benson, K. K. Holmes, A. K. Pau, and J. E. Kaplan, "Prevention and treatment of opportunistic infections in HIV-infected adults and adolescents: updated guidelines from the centers for disease control and prevention, national institutes of health, and HIV medicine association of the infectious diseases society of America," Clinical Infectious Diseases, vol. 58, no. 9, pp. 1308-1311, 2014.

[18] S. Tasaka, N. Hasegawa, S. Kobayashi et al., "Serum indicators for the diagnosis of pneumocystis pneumonia," Chest, vol. 131, no. 4, pp. 1173-1180, 2007.

[19] F. Esteves, S. S. Calé, R. Badura et al., "Diagnosis of Pneumocystis pneumonia: evaluation of four serologic biomarkers," Clinical Microbiology and Infection, vol. 21, no. 4, pp. 379.el-379.e10, 2015.

[20] S. Tasaka and H. Tokuda, "Recent advances in the diagnosis of Pneumocystis jirovecii pneumonia in HIV-infected adults," Expert Opinion on Medical Diagnostics, vol. 7, no. 1, pp. 85-97, 2013.

[21] F. Esteves, C.-H. Lee, B. De Sousa et al., “(1-3)-Beta-D-glucan in association with lactate dehydrogenase as biomarkers of Pneumocystis pneumonia (PcP) in HIV-infected patients," European Journal of Clinical Microbiology and Infectious Diseases, vol. 33, no. 7, pp. 1173-1180, 2014. 
[22] J. Quist and A. R. Hill, "Serum lactate dehydrogenase (LDH) in Pneumocystis carinii pneumonia, tuberculosis, and bacterial pneumonia," Chest, vol. 108, no. 2, pp. 415-418, 1995.

[23] D. R. Boulware, K. H. Hullsiek, C. E. Puronen et al., "Higher levels of CRP, D-dimer, IL-6, and hyaluronic acid before initiation of Antiretroviral Therapy (ART) are associated with increased risk of AIDS or death," Journal of Infectious Diseases, vol. 203, no. 11, pp. 1637-1646, 2011.

[24] B. O. Porter, G. L. Ouedraogo, J. N. Hodge et al., “d-Dimer and CRP levels are elevated prior to antiretroviral treatment in patients who develop IRIS," Clinical Immunology, vol. 136, no. 1, pp. 42-50, 2010.

[25] L. H. Kuller, R. Tracy, W. Belloso et al., "Inflammatory and coagulation biomarkers and mortality in patients with HIV infection," PLoS Medicine, vol. 5, no. 10, article e203, 2008.

[26] C. Montón, A. Torres, M. El-Ebiary, X. Filella, A. Xaubet, and J. P. De La Bellacasa, "Cytokine expression in severe pneumonia: a bronchoalveolar lavage study," Critical Care Medicine, vol. 27, no. 9, pp. 1745-1753, 1999.

[27] C.-W. Chou, F.-C. Lin, H.-C. Tsai, and S.-C. Chang, "The importance of pro-inflammatory and anti-inflammatory cytokines in Pneumocystis jirovecii pneumonia," Medical Mycology, vol. 51, no. 7, pp. 704-712, 2013.

[28] O. Dienz and M. Rincon, "The effects of IL-6 on CD4 T cell responses," Clinical Immunology, vol. 130, no. 1, pp. 27-33, 2009.

[29] W. Chen, E. A. Havell, F. Gigliotti, and A. G. Harmsen, "Interleukin-6 production in a murine model of Pneumocystis carinii pneumonia: relation to resistance and inflammatory response," Infection and Immunity, vol. 61, no. 1, pp. 97-102, 1993.

[30] X. Iriart, B. Witkowski, C. Courtais et al., "Cellular and cytokine changes in the alveolar environment among immunocompromised patients during Pneumocystis jirovecii infection," Medical Mycology, vol. 48, no. 8, pp. 1075-1087, 2010.

[31] K. W. Moore, R. de Waal Malefyt, R. L. Coffman, and A. O'Garra, "Interleukin-10 and the interleukin-10 receptor," Annual Review of Immunology, vol. 19, pp. 683-765, 2001.

[32] S. Ruan, C. Tate, J. J. Lee, T. Ritter, J. K. Kolls, and J. E. Shellito, "Local delivery of the viral interleukin-10 gene suppresses tissue inflammation in murine Pneumocystis carinii infection," Infection and Immunity, vol. 70, no. 11, pp. 6107-6113, 2002.

[33] M. Denis and E. Ghadirian, "Dysregulation of interleukin 8 , interleukin 10 , and interleukin 12 release by alveolar macrophages from HIV type 1-infected subjects," AIDS Research and Human Retroviruses, vol. 10, no. 12, pp. 1619-1627, 1994. 


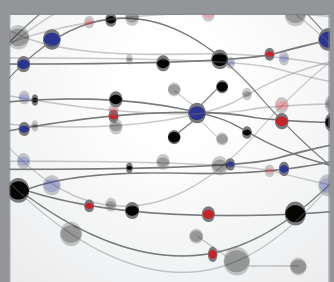

The Scientific World Journal
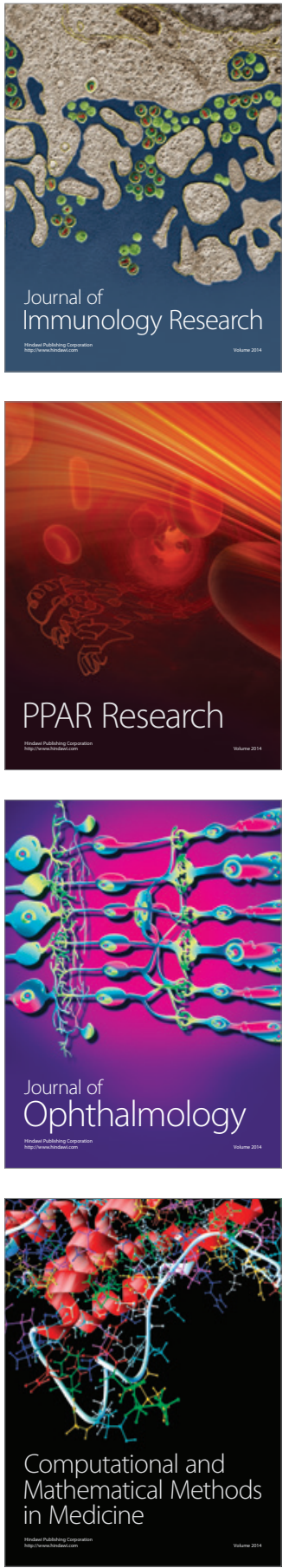

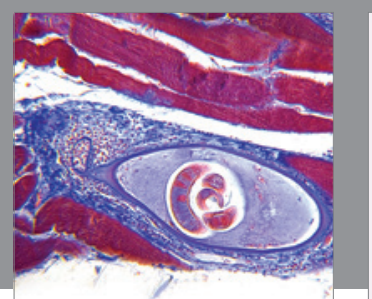

Gastroenterology Research and Practice

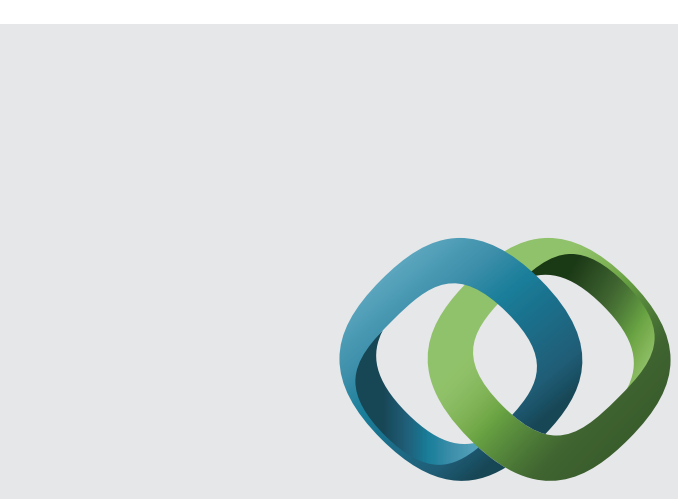

\section{Hindawi}

Submit your manuscripts at

http://www.hindawi.com
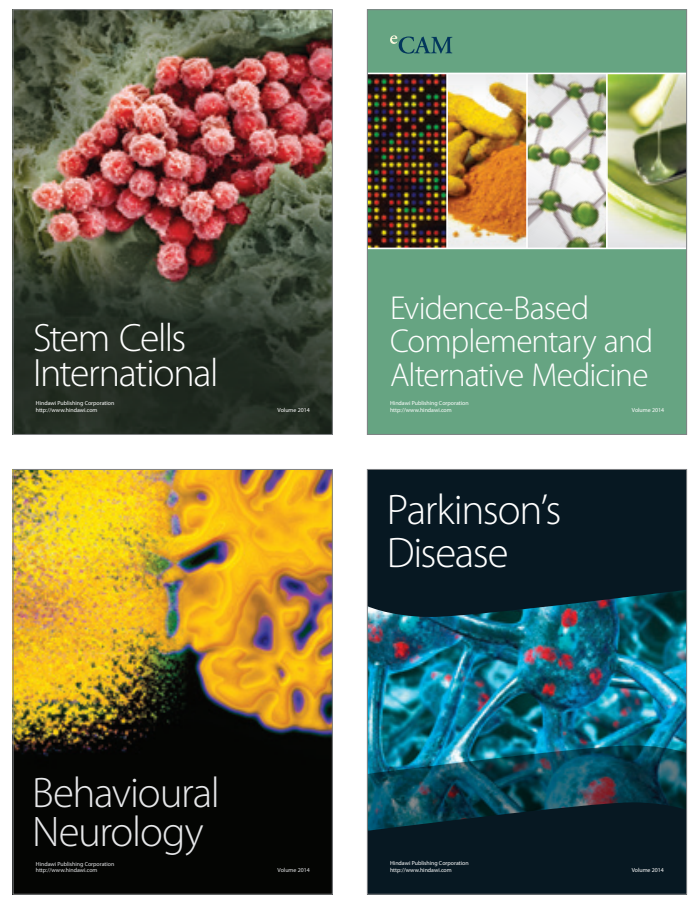
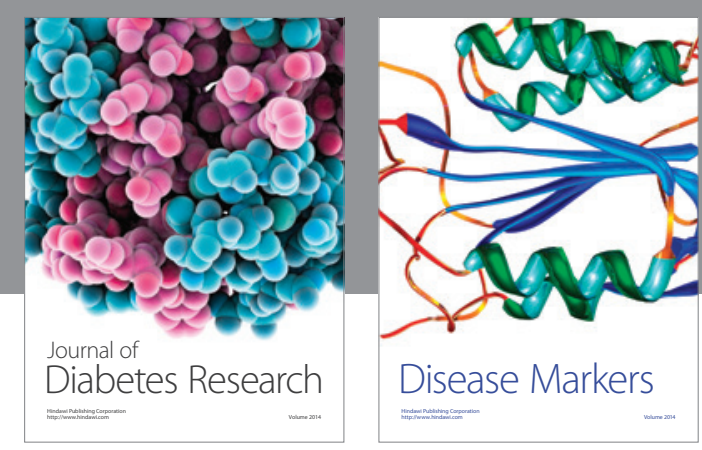

Disease Markers
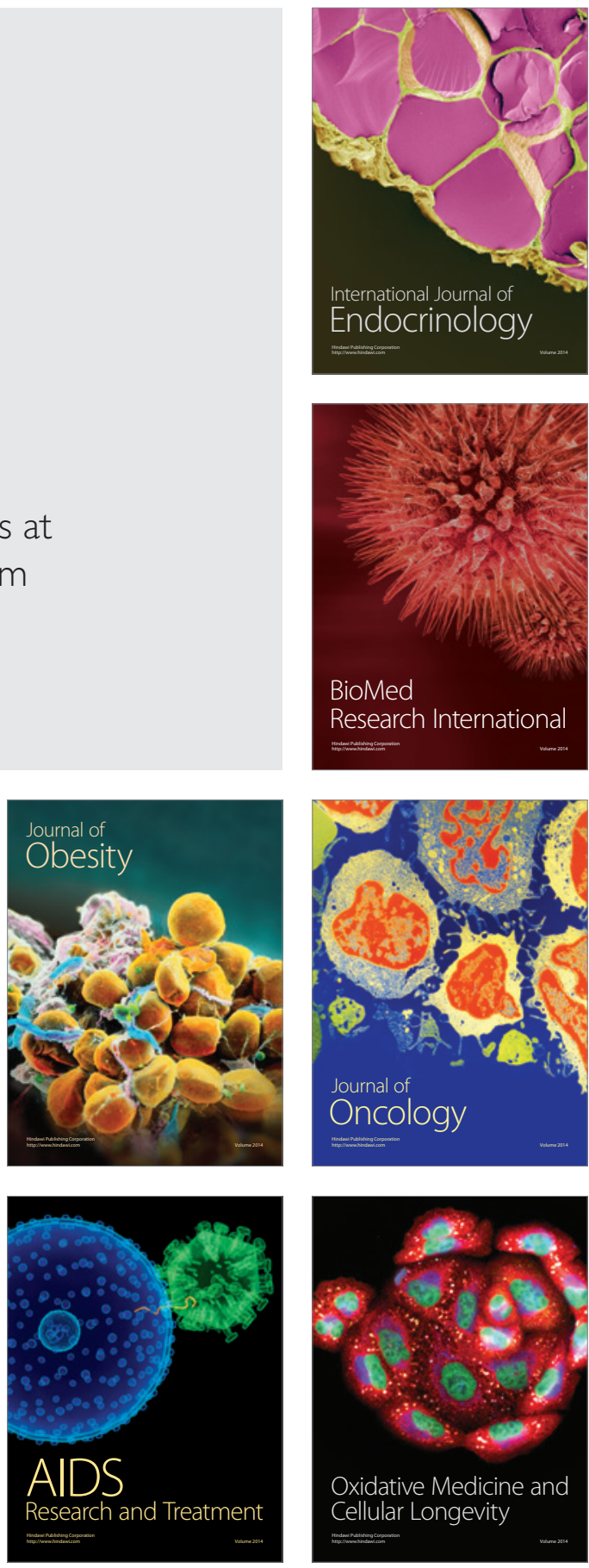